\title{
Why the long face? Comparative shape analysis of miniature, pony, and other horse skulls reveals changes in ontogenetic growth
}

\author{
Laura Heck $^{1}$, Marcelo R Sanchez-Villagra ${ }^{1}$, Madlen Stange ${ }^{\text {Corresp. } 2}$ \\ 1 Palaeontologisches Institut und Museum, University of Zürich, Zürich, Switzerland \\ 2 Department of Biology \& Redpath Museum, McGill University, Montréal, Quebec, Canada \\ Corresponding Author: Madlen Stange \\ Email address: stange.madlen@gmail.com
}

Background. Much of the shape variation found in animals is based on allometry and heterochrony. Horses represent an excellent model to investigate patterns of size-shape variation among breeds that were intentionally bred for extreme small and large sizes.

Methods. We tested whether ponies (wither height $<148 \mathrm{~cm}$ ) have a diverging size-shape relationship in skull shape as compared to regular-sized horse breeds (wither height $>148 \mathrm{~cm}$, here-after called horses) during ontogenetic growth. We used a dataset of 194 specimens from 25 horse and 13 pony breeds, two of which are miniature breeds (wither height $<96.5 \mathrm{~cm}$ ) - Falabella, Shetland. We applied three-dimensional geometric morphometrics, linear measurements, and multivariate analyses

(Procrustes ANOVAs) to quantitatively examine and compare the ontogenetic trajectories between ponies and horse breeds with an emphasis on the miniature breeds as an extreme case of artificial selection on size. Additionally, we tested for juvenile characteristics in adult horse and miniature breeds that could resemble "paedomorphosis" - retention of juvenile characteristics in adult stage; e.g. large eyes, large braincase-to-face-relationship, and large head-to-body relationship.

Results. Allometric regression of size on shape revealed that $42 \%$ of shape variation could be explained by variation in size in all breeds. The ontogenetic trajectories of ponies and horses vary in slope and therefore in rate of change per unit size and length. The differences in trajectory lengths and slopes result in ponies having a similar skull shape in an older age stage than horses of the same size in a younger age stage. This pattern could cause the generally perceived "paedomorphic" appearance of ponies. Miniature breeds have larger heads in relation to wither height compared to horses, a nonpaedomorphic feature in horses specifically. Also rostra (faces) are longer in adult individuals than in juveniles across all kinds of breeds. This pattern can be explained by the long-face hypothesis for grazing ungulates and could possibly be caused by the mismatch of selection by humans for shorter rostra and the dentition of ruminants.

Conclusions. Miniature breed specimens do not exhibit any of the classical mammalian "paedomorphic" features (large orbits, large heads), except for the adult Falabella that has enlarged orbits, possibly because they are herbivorous ungulates that are affected by functional and metabolic constraints related to low nutrient-food consumption. Instead ponies, including miniature breeds, have faster and shorter ontogenetic growth compared to horses, resulting in adult pony skulls looking in part like juvenile horse skulls. 


\section{Why the long face? Comparative shape analysis of}

\section{2 miniature, pony, and other horse skulls reveals changes in}

\section{3 ontogenetic growth}

5 Laura Heck $^{1}$, Marcelo R. Sánchez-Villagra ${ }^{1}$, Madlen Stange ${ }^{2}$

6

$7 \quad{ }^{1}$ Palaeontologisches Institut und Museum, University of Zürich, Zürich, Switzerland

$8{ }^{2}$ Department of Biology \& Redpath Museum, McGill University, Montréal, Quebec, Canada 9

10 Corresponding Author:

11 Madlen Stange ${ }^{2}$

12859 Sherbooke Street West, Montreal, QC, H3A 2K6, Canada

13 Email address: stange.madlen@gmail.com 


\section{Abstract}

16 Background. Much of the shape variation found in animals is based on allometry and

17 heterochrony. Horses represent an excellent model to investigate patterns of size-shape variation

18 among breeds that were intentionally bred for extreme small and large sizes.

19 Methods. We tested whether ponies (wither height $<148 \mathrm{~cm}$ ) have a diverging size-shape relationship in skull shape as compared to regular-sized horse breeds (wither height $>148 \mathrm{~cm}$, here-after called horses) during ontogenetic growth. We used a dataset of 194 specimens from 25 horse and 13 pony breeds, two of which are miniature breeds (wither height $<96.5 \mathrm{~cm}$ ) Falabella, Shetland. We applied three-dimensional geometric morphometrics, linear measurements, and multivariate analyses (Procrustes ANOVAs) to quantitatively examine and compare the ontogenetic trajectories between ponies and horse breeds with an emphasis on the miniature breeds as an extreme case of artificial selection on size. Additionally, we tested for juvenile characteristics in adult horse and miniature breeds that could resemble "paedomorphosis" - retention of juvenile characteristics in adult stage; e.g. large eyes, large braincase-to-face-relationship, and large head-to-body relationship.

Results. Allometric regression of size on shape revealed that $42 \%$ of shape variation could be explained by variation in size in all breeds. The ontogenetic trajectories of ponies and horses vary in slope and therefore in rate of change per unit size and length. The differences in trajectory lengths and slopes result in ponies having a similar skull shape in an older age stage than horses of the same size in a younger age stage. This pattern could cause the generally perceived "paedomorphic" appearance of ponies. Miniature breeds have larger heads in relation to wither height compared to horses, a non-paedomorphic feature in horses specifically. Also rostra (faces) are longer in adult individuals than in juveniles across all kinds of breeds. This pattern can be explained by the long-face hypothesis for grazing ungulates and could possibly be caused by the mismatch of selection by humans for shorter rostra and the dentition of ruminants.

40 Conclusions. Miniature breed specimens do not exhibit any of the classical mammalian "paedomorphic" features (large orbits, large heads), except for the adult Falabella that has enlarged orbits, possibly because they are herbivorous ungulates that are affected by functional and metabolic constraints related to low nutrient-food consumption. Instead ponies, including miniature breeds, have faster and shorter ontogenetic growth compared to horses, resulting in adult pony skulls looking in part like juvenile horse skulls. 


\section{Introduction}

Allometry, shape change associated with size change, accounts for much of newly generated shape changes (Wilson, 2018). Patterns of shape variation and allometry during ontogeny, that is the size-shape relationship during an organisms growth, have been studied in many domesticated animals such as dogs (Wayne, 1986; Morey, 1992; Goodwin, Bradshaw \& Wickens, 1997; Geiger et al., 2017; Werneburg \& Geiger, 2017), pigs (Hilzheimer, 1926; Evin et al., 2017), sheep (Geist, 1974), guinea pigs (Kruska \& Steffen, 2013), and horses (Radinsky, 1984; Goodwin, Levine \& McGreevy, 2008). Recent advances in the study of shape variation, especially through the advancement of statistical methods for the analysis of multivariate geometric morphometric data, have increased our knowledge on how shape variation arises and how variation is patterned (Adams et al., 2004; Adams, Rohlf \& Slice, 2013).

Horses exhibit a large size range from $84 \mathrm{~cm}$ (Falabella) to $178 \mathrm{~cm}$ wither height (Shire). Ponies are defined by a wither height less than $148 \mathrm{~cm}$ (FEI, 2016). Ponies are derived from selection on larger breeds (Hendricks, 2007). Extremely small ponies, so-called miniature breeds, formally belong to the group of ponies. Miniature breeds are defined as horse breeds with a wither height of less than $96.52 \mathrm{~cm}$ (38 in) ("World Class Miniature Horse Registry") and have been purposely bred for extreme small size. The smallest horse breed, the Falabella, originates from Argentina. The breed was first mentioned in the middle of the $19^{\text {th }}$ century when very small individuals of Criollo horses were encountered in the Argentinian Pampa (Hendricks, 2007). After obtaining a few individuals and starting a breeding program with miniature horses, the name giver of the breed, Juan Falabella, added small individuals of English Thoroughbred, Criollo, and the also miniature breed Shetland pony to achieve a harmonious conformation with a wither height lower than $84 \mathrm{~cm}$. The Shetland pony, which was strongly interbred with the Falabella due to its small wither height $(\max .106 \mathrm{~cm})$, originates from the Shetland Islands, Scotland. It is among the oldest known horse breeds and was mostly bred locally on the islands for croft works. When an act of British Parliament, however, prohibited child labour in the coalmines in 1847 , the demand for these small robust ponies, as a replacement, increased drastically. Over the last century, numerous individuals have been exported, mainly being used for driving or as a first mount for children (Hendricks, 2007).

In the following we investigate ontogenetic trajectories of ponies (wither height $<148$ $\mathrm{cm}$ ) including two miniature breeds, and regular-sized horse breeds (wither height $>148 \mathrm{~cm}$ ) 
77 using three-dimensional geometric morphometrics (3D GM). We will refer to regular-sized horse 78 breeds as 'horses' for simplicity. If not stated otherwise ponies always include the miniature breeds. We will highlight two miniature breeds - Falabella and Shetland, and their position in

80

81 82 morphospace. Osteological samples of the Falabella are so rare that we have quantified skull shape from the only complete skull specimen available in public museum collections. The comparative analysis of these extreme cases of miniaturisation with other breeds will give us insights into differential growth patterns in horses due to artificial selection for size.

Further, we aim to shed light on the perceived juvenile appearance of miniature and pony breeds when compared to horses by assessing "paedomorphosis" in its broadest sense - the resemblance of an adult form to a juvenile of a sister group. We are aware that breeds are not individual species, for that reason we do not claim to study paedomorphosis in the strict sense. However, there are certain features in Falabella and Shetland adult skulls that raise the question, whether they have retained juvenile appearance. For example, the adult Falabella skull exhibits a round braincase that can partly be seen in the other miniature breed - the Shetland, but not in the larger Welsh (Fig. 1). Generally, juvenilized phenotypic features are differences in body proportions, e.g. a larger head and shorter limbs (Gould, 1980), and differences in cranial proportions, such as larger eyes, a more prominent and bulging cranium, and a short rostrum in combination with an enlarged braincase (Gould, 1980; Wayne, 1986; Tamagnini, Meloro \& Cardini, 2017; Evin et al., 2017). In particular, the shortening of the face portion of the skull in smaller taxa versus the elongation of the face portion in larger related taxa has gained some attention over the past years and has been formalized as the cranial evolutionary allometry hypothesis (CREA) (Tamagnini, Meloro \& Cardini, 2017). To approach the quantification of juvenilized shape we use linear measurements derived from the 3D GM dataset for all age classes and all breeds and calculate ratios of length that reflect the typical paedomorphic traits of larger eyes, shorter face, and smaller head to body ratio in ponies.

\section{Materials \& Methods}

Specimens analyzed and determination of age classes

A total of 194 juvenile and adult crania were analyzed (Table S1). We examined specimens from the following collections: Museum für Naturkunde Berlin (MfN Berlin, Germany), Institut für 
106 Haustierkunde (Christian-Albrechts-Universität of Kiel, Germany), Museum für Haustierkunde 107 „Julius Kühn“ (University of Halle, Germany), Naturhistorisches Museum Wien (NHW Vienna, 108 Austria), and Museo de la Plata (MLP La Plata, Argentina). The dataset includes 38 horse

109 breeds, ranging from the smallest (Falabella) to the largest breed (Shire) (Table S1). Of the 38

110 breeds, 13 are considered ponies two of which are miniature breeds as indicated in brackets:

111 Bosnian pony (bos), Exmoor pony (exm), Falabella (fab) (miniature), German Riding pony (grp),

112 Icelandic Horse (ice), Indian pony (ind), Konik (kon), Mongolian (mon), Scottish pony (scp),

113 Shetland pony (she) (miniature), Togo pony (tog), and Welsh (wel). 25 breeds are considered

114 regular-sized breeds or horses: Anglo-Norman (ano), Arab (arb), Birkenfelder (bif), Belgian

115 Draft (blg), Clydesdale (cds), Galician Farm Horse (gbh), Grisons (Graubündner) (grb),

116 Hannoverian (han), Hackney (hny), Holstein (hol), Hungarian (hun), Huzule (huz), Kladrubian

117 (kdr), Kosarian (kos), Lipizzan (lpz), Nonius (nos), Norik (nor), Oldenburgian (odb), Pinzgau

118 (piz), Polish Farm Horse (pll), Seneca Sarajevo (ses), Shire (shi), Styrian (stm), Suffolk (suf),

119 English Thoroughbred (thb), Trakehner (trk).

120 Prior to analyses, each specimen was categorized into an age class from 0 to 6 using an

121 identification key for dental eruption (Habermehl, 1975) with: 0 - dental eruption after birth, 1 -

122 eruption of the first pair of deciduous incisors, 2 - eruption of the second pair of deciduous

123 incisors, 3 - eruption of the third pair of deciduous incisors, 4 - eruption of the first molar, 5 -

124 eruption of the second molar, and 6 - eruption of the third molar (Table S1). Weaning occurs

125 around the end of age class 2 and the beginning of age class 3 (at around six months), while

126 sexual maturity is reached at the beginning of age class 4 (at around one year) and skeletal

127 maturity is reached in age class 6 (around 4 years). Notably, the dataset contains only a single

128 specimen of Falabella, to our knowledge the currently only complete skull from a museum

129 collection to be measured.

130 Collection of shape data

131 Cranial shapes were analysed using landmark-based geometric morphometric (GMM)

132 approaches. The crania were measured in three-dimensions (3D) using a MicroScribe ${ }^{\circledR}$ MLX6

133 (Revware, Inc., Raleigh, North Carolina, USA; accuracy: $0.076 \mathrm{~mm}$ ) and a total of 60 type I and

134 type II landmarks (Bookstein, 1990) (Table S2, Figure S1) were collected. The dorsal and ventral

135 sides of the crania were measured separately and the landmark datasets were subsequently 
136 combined using three reference landmarks (numbered 1, 2, and 33, Figure S1) in the

137 Microscribe ${ }^{\circledR}$ software MUS (Revware, Inc., Raleigh, North Carolina, USA). All subsequent

138 analyses were conducted using R v.3.5.2 (R Core Team, 2016) and related R packages for the

139 analyses of geometric morphometric data: geomorph v. 3.1.2 (Adams et al., 2018) and shapes v.

140 1.2.4 (Dryden, 2018). The code that was used for the following analyses of 3D GM data can be

141 found as a supplement in Code_and_Results_Falebella_pub.rmd.

\section{$1423 D$ Geometric morphometric analyses}

143 General Procrustes Analysis (GPA) (Rohlf \& Slice, 1990) was performed on the 3D shape data

144 to eliminate the effects of size, orientation, and scaling. GPA translates, rotates, and scales all

145 specimens' coordinates so their centroids coincide and are scaled to unit centroid size, and the

146 squared summed distances between matching landmarks are minimized. Due to its bilateral

147 symmetry, only the symmetric component of the cranium was used in the subsequent analyses

148 (Klingenberg, Barluenga \& Meyer, 2002; Kolamunnage \& Kent, 2003). We calculated centroid

149 size for each landmark configuration.

150 To visualize morphospace occupation of the age classes of miniature breeds and horses along

151 major axes of variance, we performed a principal component analysis (PCA) using the co-

152 variance matrix of Procrustes scores retained from the GPA. We calculated mean shapes for each

153 age class of horse breeds as well as for the Shetland and Falabella to visualize shape differences

154 with age.

\section{Characterizing cranial ontogenetic shape trajectories of ponies and horses}

156 For subsequent analyses of ontogenetic size-shape co-variation (allometry) between and within

157 pony and horses we performed linear regressions (Procrustes ANOVA) of shape (Procrustes

158 coordinates) on logarithmized centroid size, and a grouping factor, type $=\mathrm{H} / \mathrm{P}$, which denotes the

159 group affiliation of each breed to either horse $(\mathrm{H})$ or pony $(\mathrm{P})$ breed as indicated in Table $\mathrm{S} 1$ and

160 raw coordinates file. To inspect the inter-specific allometric relationship between pony and horse

161 breeds we used two methods, the regression of shape on size resulting in a plot of regression

162 residuals on log centroid size (Drake \& Klingenberg, 2008) and the predicted shape approach

163 (Adams \& Nistri, 2010) that plots the first principal component from a regression of predicted

164 shape values on log centroid size. We applied a test for homogeneity of slopes (HOS) when the

165 interaction term of $\log ($ size $)$ and type was significant during Procrustes ANOVA (Collyer \& 
166 Adams, 2013; Collyer, Sekora \& Adams, 2015; Adams \& Collyer, 2016). The HOS test allowed

167 us to determine whether pony and horse breed ontogenetic allometries differed in slope distance

168 (amount of shape changes with size), slope angles (direction of shape change), or intercept.

169 Testing features of paedomorphosis in miniature breeds using linear measurements

170 Additionally, to complement the multivariate statistical analyses for differences in ontogenetic

171 trends between ponies and horses, we aimed to test for features of "paedomorphosis" in the

172 miniature breeds using only linear measurements. We define "paedomorphosis" loosely here, as

173 a general resemblance of adults in miniature breeds to juveniles in all other breeds. Typical

174 phenotypic features of paedomorphosis are differences in body proportions, e.g. a larger head

175 and shorter limbs (Gould, 1980), and differences in cranial proportions including larger eyes, a

176 more prominent and bulging cranium, and a short rostrum in combination with an enlarged

177 braincase (Gould, 1980; Wayne, 1986; Tamagnini, Meloro \& Cardini, 2017; Evin et al., 2017).

178 Paedomorphism has been claimed to describe some differences among horse breeds (Budiansky,

179 1997; Goodwin, Levine \& McGreevy, 2008), however the long-face hypothesis of grazing

180 ungulates (Spencer, 1995), that postulates that longer faces are observed in smaller forms of

181 grazing ungulates, if also true for horses, could explain lack of signs of paedomorphism in the

182 rostrum. We calculated interlandmark distances (specified below) from the three-dimensional

183 dataset in the R package geomorph (Adams et al., 2018) and calculated the ratios for the

184 following three traits:

185 Larger eyes: To test whether miniature breeds exhibit larger orbits (eyes) than regular-sized

186 breeds relative to their respective cranial lengths, we calculated the ratio of orbit length to cranial

187 length from measurements of the orbit diameter (LM 15 - 17, Table S2, Figure S1) and total

188 cranial length (LM 37 - 58, Table S2, Figure S1).

189 Shorter rostrum: To test for rostral shortening we measured the length of and the angle

190 between palate (LM 37 - 44, Table S2, Figure S1) and basicranium (LM 49 - 58, Table S2,

191 Figure S1). The angle is expected to become smaller the larger the braincase and the shorter the 192 palate becomes.

193 Smaller head to body ratio: We inspected the relationship of adult cranial length (LM 33 - 58)

$194(\mathrm{n}=128)$ and average breed wither height, which we collected from the literature for a subset of

19511 ponies and 18 horses (breeding guidelines for each breed, Table S3). We calculated the 
196 predicted adult cranial length of the miniature breeds as derived from linear regression of adult

197 cranial lengths from horse breeds (Verzani, 2014) and compared it to their actual cranial lengths.

198 The adult cranial length to wither height ratio in relation to breed is used to investigate a possible

199 minimal limit in cranial length in the investigated breeds.

200 Results

201 Characterization of cranial shape of miniature and horse breeds

202 We calculated and visualized the mean shape for each age class from Procrustes shape data, as

203 well as that of the adult stage of the two miniature breeds (Fig. 2). A description of the different

204 age classes $(0,3,6)$ and the adult crania of the Falabella and Shetland pony are presented in

205 Table 1 . The juvenile age classes of horses are characterized by a very broad and short cranium

206 with a bulging anterior-dorsal part of the braincase (Fig. 2). During growth, the cranium

207 elongates (rostrum stronger than the anterior part of the braincase) and the anterior-dorsal part of

208 the cranium flattens. The orbit size decreases in relation to the complete cranium.

209 Cranial ontogenetic shape change of pony and horse breeds

210 PCA (Fig. 3A) reveals that the ontogenetic stages 0-6 separate in PC1-PC2 space along PC1

211 from adult (PC1 negative) to juvenile age stages (PC1 positive). The first $\mathrm{PC}$ accounts for $47.1 \%$

212 of the total shape variation. A gap in the shape space between age classes 0-2 and 3-6 is visible.

213 Also, we can observe that cranial shape among early ontogenetic stages is more similar to each

214 other than cranial shape of the adult stage, where the scatter becomes larger. When comparing

215 the miniature breeds to horses in shape space, it becomes evident that the Shetland specimens

216 align with the respective age classes of larger breeds, but constitute the most 'youthful' cohort of

217 the respective stages (Fig. 3A). The adult skull (age class 6) of the smallest of all horse breeds,

218 the Falabella specimen, clusters most within age stages 3 and 4 of regular-sized breeds (Figs. 3A;

219 4). The same PCA highlighted by group - miniature breeds, ponies, and horses - (Fig.3B)

220 visualizes that horse breeds scatter more along PC2. The contrast of shape change along PC 1

221 (Fig. 3C) demonstrates that the braincase undergoes larger changes than the rostrum. 
222

223 We tested for allometry and differences in allometric growth between ponies and horses

224 performing Procrustes ANOVAs (analyses of variance). Regression of skull shape (Procrustes

225 coordinates) on log centroid size for the entire sample (ponies and horses) shows a strong effect

226 of size on shape $\left(\mathrm{R}^{2}=0.42, \mathrm{p}=0.001\right)$. Adding "type" as an additional covariate yielded that

227 mean shapes of ponies and horses $(F=9.201, \mathrm{Z}=6.488, \mathrm{p}=0.001)$ as well as their allometries

$228(\mathrm{~F}=3.613, \mathrm{Z}=4.141, \mathrm{p}=0.001)$ differ. Specifically, they differ in rate of change $(\mathrm{Z}=4.125$,

$229 \mathrm{p}=0.001$ ) and slope (angle $=21.25 \mathrm{deg}, \mathrm{r}=0.93, \mathrm{Z}=5.28, \mathrm{p}=0.001)$. This result can be visually

230 assessed in Figure 4B. A test of least square (LS) means revealed no difference in intercept ( $Z=-$

231 1.089, $\mathrm{p}=0.856$ ). Generally, ponies have attained more maturity than horses at the same size,

232 while exhibiting the same skull shape as horses. The position of the adult Falabella (age class 6)

233 skull in the shape-size regression (Fig. 4A) and allometric trend (Fig. 4B) indicate that the

234 Falabella skull shape resembles younger horse breed shapes at the same size.

235

236

237

238

239

240

241

242

243

244

245

246

247

248

249

250

\section{Testing features of "paedomorphosis" in miniature breeds}

During ontogenetic growth of horses we observe that orbits grow smaller in relation to cranial length (Figure $5 \mathrm{~A}$ ), and the basicranium becomes shorter relative to the length of the rostrum (Figure $5 \mathrm{~B}$ ). The angle between the basicranium and palate does not differ significantly among the different age stages (Figure $5 \mathrm{C}$ ). The growth pattern of Shetland ponies is similar to that of horses and do not show any signs of enlarged orbits or shortened rostra or increased brain case in the adult stage (Figure $5 \mathrm{~A}-\mathrm{C}$ ). The adult Falabella exhibits larger orbits (Figure $5 \mathrm{~A}$ ) but otherwise no other juvenile features regarding the rostrum or braincase (Figure 5 A-C). The predicted cranial length of the Falabella and Shetland derived from linear regression of adult cranial lengths from horse breeds is $24.6 \mathrm{~cm}$ and $31.1 \mathrm{~cm}$ respectively, which contrast to their actual lengths of $35.6 \mathrm{~cm}$ and about $39 \mathrm{~cm}$, respectively. Both actual cranial lengths fall slightly outside of the $95 \%$ prediction interval (Figure $5 \mathrm{D}$ ). The cranial length at the upper prediction limit raises the question whether ponies are constrained to have larger crania. Examination of the cranial length to wither height ratio in relation to breed ordered by increasing maximal wither height supports that the adult miniature breeds, Shetland and Falabella, have larger crania relative to wither height than their horse cognates (Figure $5 \mathrm{E}$ ). 


\section{Discussion}

252

253

254

255

256

257

258

259

260

261

262

263

264

265

266

267

268

269

270

271

272

273

274

275

276

277

278

279

280

281

Horses show allometric cranial growth where the juvenile specimens are significantly different in cranial shape from the adult specimens (Sánchez-Villagra et al., 2017) and this study (42\%), as has been attested for other domesticated species (Wilson, 2018) and mammals in general (Porto et al., 2009), The largest shape differences in PC1-PC2 shape space in our sample can be found between the age classes $0-1$ and 2-6. The difference between those two age clusters is most likely caused by the low sample size in age class $2(n=2)$ and it is likely that the ontogenetic trajectory for horses and ponies would form a continuum if age class 2 would contain more specimens. To our knowledge, based on our examination of many museum collections, specimens of that age class are rarely available.

Ponies and horses show differences in ontogenetic trajectory direction or angle but not in intercept, which indicates that juveniles of all breeds start with a similar skull shape but diverge during ontogenesis. Furthermore, ponies (including miniature breeds) develop faster than regular-sized breeds and stop growth earlier. Therefore, horses develop adult cranial shapes that ponies do not reach during growth. As a result, a younger horse specimen and an older pony specimen can exhibit the same skull shape. This pattern could explain why ponies look like juvenilized adult horses. Only the miniature breed Falabella, but not the Shetland, exhibits a "paedomorphic" feature: enlarged orbits relative to cranial length in its final age state.

Given our results, we would like to emphasize that there are likely inter-breed differences in skull shape at birth and possibly prenatally but shape data for those age classes are scarce. We have preliminary evidence that skull shape differences among pony breeds arise prenatally. We compared the ontogenetic trajectories of the Shetland as a miniature breed and the Welsh as a regular pony (Figure S2, not presented in main text due to small sample size). Apart from dogs (Werneburg \& Geiger, 2017), this pattern has also been hypothesized in pigs (Evin et al., 2017), and needs to be further investigated in horses including more breeds.

We investigated whether ponies, when compared to horses, represent a case of craniofacial evolutionary allometry (CREA) (Cardini \& Polly, 2013; Cardini et al., 2015; Tamagnini, Meloro \& Cardini, 2017). CREA predicts that larger forms are long-faced and smaller forms short-faced as a sign of paedomorphism. As an approximation for braincase-toface relationship we calculated the ratio of basicranium-to-palate lengths for miniature and horse breeds. We found no signs of CREA. In contrast, we found that our results are in accordance 
282 with the long-face hypothesis for grazing ungulates (Spencer, 1995). The long-face hypothesis

283 does not offer a definite explanation why longer faces are observed in smaller forms of grazing

284 ungulates. In the case of the miniaturized horses, we propose that this could be due to constraints

285 in tooth morphology and the feeding style of grazing. Among veterinarians, it is commonly

286 known that miniature horse breeds have a higher requirement for veterinary dentist procedures,

287 due to their almost regular horse-sized teeth (Wilson, 2012). The same health-related problem

288 has been shown for pet rabbits, which experience a rostral shortening through domestication

289 without a change in dentition (Böhmer \& Böhmer, 2017). These functional constraints have been

290 investigated also in humans showing that miniature forms tend to have relatively larger teeth

291 than regular-sized forms (Shea \& Gomez, 1988). Since horses and ponies feed on a very nutrient

292 poor diet, they are in need of a highly specialized feeding apparatus to ensure the best energy

293 recovery possible. A strong shortening of the rostrum, as can be found in some dog and pig

294 breeds (Geiger \& Haussman, 2016; Evin et al., 2017), is most likely possible due to their energy

295 rich diet (carnivore/omnivore) that can be exploited with fewer, smaller, or differently placed

296 teeth. In cows, which also feed on nutrient poor grass, one case of rostral shortening is known:

297 the Niata breed (Veitschegger et al., 2018); this was likely possible due to the more efficient

298 uptake of nutrients through rumination. There is evidence of rostral shortening in a extinct

299 herbivorous, non-ruminant browsing mammal clade, the short-faced kangaroo subfamily

300 Sthenurinae (Prideaux, 2004). Yet to our knowledge, there is no evidence of the existence of a

301 grazing ungulate with rostral shortening.

302

Large heads and increased head-to-body ratio has been shown to be a paedomorphic

303 feature in other domesticated species, namely dogs and chicken (Alberch et al., 1979; Gould,

304 1980; Wayne, 2001), but does not associate with paedomorphosis in horses as new born foals

305 have shorter rostra than adult individuals because teeth development drives rostral lengthening;

306 as well as foals having relatively longer legs (Habermehl, 1975; van Heel et al., 2006; Goodwin,

307 Levine \& McGreevy, 2008) (Table 1). The long legs in horses are a necessity for survival, since

308 new born foals are very precocial and need to keep up with the herd from day one. Our study did

309 not compare the actual limb to head length ratio which has been proposed as a sign for

310 paedomorphism (Goodwin, Levine \& McGreevy, 2007, 2008), but used wither height as a proxy

311 for size. We found that the miniature breeds have larger heads relative to body size 
312 (approximated by wither height) when compared to horse breeds. So adult miniature breeds do

313 not exhibit the juvenile state of a horse in respect to head-to-body size ratio.

314 Regarding the adult Falabella skull and the case of the Falabella in general, we could not

315 support our first subjective impression that the Falabella must be a "paedomorphic" horse.

316 However, this impression probably derived from the very round anterior-dorsal part of the

317 braincase, whose geometric morphometric quantification by using true landmarks eluded us due

318 to the lack of sutures in that portion of the cranium, but the curvature can be seen in the

319 photograph of the Falabella cranium (Fig. 1A). Additionally, the Falabella does exhibit a less

320 downward curved rostrum than adults of regular-sized breeds (Fig. 1). For a better assessment of

321 a rounded cranium roof, future investigations are advised to use semi-landmarks or polygons

322 (MacLeod, 2013; Collyer, Sekora \& Adams, 2015).

\section{Conclusions}

324 We investigated patterns of allometry during ontogeny in horses as a case of directional artificial

325 selection for extreme size differences in domesticated horses. Wither heights range from $84 \mathrm{~cm}$

326 in the Falabella to $178 \mathrm{~cm}$ in the Shire horse. We looked at allometric trends between ponies and

327 horses and investigated typical patterns of "paedomorphosis", defined as juvenile appearance in

328 adult stage, with an emphasis on miniature horses as an extreme case of size selection. We found

329 that ponies and horses have shifted ontogenetic trajectories that vary in length but not in

330 direction or angle, with the consequence that ponies exhibit similar skull shapes at older age

331 stages as horses at younger age stages. This pattern is a potential source of the perceived

332 juvenilized skull shape of ponies, additionally to features of the postcranial architecture, namely

333 general small size or short limbs, or behavioral aspects as has been show in dogs (Hare \&

334 Woods, 2013), such as the use of body language (Goodwin, Bradshaw \& Wickens, 1997) or

335 facial expressions (Waller et al., 2013).

336 Other than the overall shape development of ponies halting earlier than of horses we find

337 no other evidence of "paedomorphic" features, as enlarged orbits, shorter faces, or increased

338 head-to-body ratio, as it is the case in dogs and pigs, except for the adult Falabella skull.

339 Miniature breeds (Falabella and Shetland) have increased skull-to-body ratio when compared to

340 horse breeds. This could be due to the very essence of horses and ponies, that is being a grazing 
341 ungulate as postulated in the long-face hypothesis (Spencer, 1995). We propose functional and

342 metabolic constraints rather than flight responses as a potential driver of this pattern.

\section{Acknowledgements}

344 We thank the many institutions and people giving us access to their collections: Christiane Funk

345

346

347

348

349

350

351

352

353

354

355

356

357

358

359

360

361

362

363

364

365

366

367

368 and Frieder Mayer (MfN Berlin, Germany), Renate Lücht (Institut für Haustierkunde, ChristianAlbrechts-Universität of Kiel, Germany), Renate Schafberg (Museum für Haustierkunde „Julius Kühn“, University of Halle, Germany), Frank Zachos, Alexander Bibl, Konstantina Saliari and Erich Pucher (NHW Vienna, Austria), and Alfredo Carlini (MLP La Plata, Argentina). We thank Laura A.B. Wilson, Madeleine Geiger for comments on an earlier version of the manuscript, and Emma Sherratt and Eric Scott for their helpful comments during the review process.

\section{References}

Adams DC, Collyer ML. 2016. On the comparison of the strength of morphological integration across morphometric datasets. Evolution 70:2623-2631. DOI: 10.1111/evo.13045.

Adams DC, Collyer ML, Kaliontzopoulou A, Sherratt E. 2018. Geomorph: Software for geometric morphometric analyses. R package version 3.0.7.

Adams DC, Nistri A. 2010. Ontogenetic convergence and evolution of foot morphology in European cave salamanders (Family: Plethodontidae). BMC Evolutionary Biology 10:216. DOI: $10.1186 / 1471-2148-10-216$.

Adams DC, Rohlf FJ, Slice DE. 2013. A field comes of age: Geometric morphometrics in the 21st century. Hystrix 24:7-14. DOI: 10.4404/hystrix-24.1-6283.

Adams DC, Rohlf FJ, Slice DE, Adams DC, Rohlf FJ, Geometric DES, Adams DC. 2004. Geometric morphometrics: Ten years of progress following the 'revolution.' Italian Journal of Zoology 71:5-16. DOI: 10.1080/11250000409356545.

Alberch P, Gould S, Oster G, Wake D. 1979. Size and Shape in Ontogeny and Phylogeny. Paleobiology 5:296-31.

Böhmer C, Böhmer E. 2017. Shape Variation in the Craniomandibular System and Prevalence of Dental Problems in Domestic Rabbits: A Case Study in Evolutionary Veterinary Science. Veterinary Sciences 4:5. DOI: 10.3390/vetsci4010005. 
369 Bookstein FL. 1990. Introduction to methods for landmark data. In: Rohlf FJ, Bookstein FL eds.

370

371

372

373

374

375

376

377

378

379

380

381

382

383

384

385

386

387

388

389

390

391

392

393

394

395

396

397

398

399

Prooceedings of the Michigan Morphometrics Workshop. Ann Arbor, MI, MI: The University of Michigan Museum of Zoology, 216-225. DOI: 10.1017/CBO9781107415324.004.

Budiansky S. 1997. The nature of horses: Exploring Equine Evolution, Intelligence, and Behavior. New York, NY: Simon \& Schuster Inc.

Cardini A, Polly PD. 2013. Larger mammals have longer faces because of size-related constraints on skull form. Nature Communications 4:1-7. DOI: 10.1038/ncomms3458.

Cardini A, Polly D, Dawson R, Milne N. 2015. Why the Long Face? Kangaroos and Wallabies Follow the Same 'Rule' of Cranial Evolutionary Allometry (CREA) as Placentals. Evolutionary Biology 42:169-176. DOI: 10.1007/s11692-015-9308-9.

Collyer ML, Adams DC. 2013. Phenotypic trajectory analysis: comparison of shape change patterns in evolution and ecology. Hystrix 24:75-83. DOI: 10.4404/hystrix-24.1-6298.

Collyer ML, Sekora DJ, Adams DC. 2015. A method for analysis of phenotypic change for phenotypes described by high-dimensional data. Heredity 115:357-365. DOI: 10.1038/hdy.2014.75.

Drake AG, Klingenberg CP. 2008. The pace of morphological change: historical transformation of skull shape in St Bernard dogs. Proceedings. Biological sciences / The Royal Society 275:71-76. DOI: 10.1098/rspb.2007.1169.

Dryden IL. 2018. shapes: Statistical Shape Analysis. R package version 1.2.4.

Evin A, Owen J, Larson G, Debiais-Thibaud M, Cucchi T, Vidarsdottir US, Dobney K. 2017. A test for paedomorphism in domestic pig cranial morphology. Biology letters 13. DOI: 10.1098/rsbl.2017.0321.

Geiger M, Evin A, Sánchez-Villagra MR, Gascho D, Mainini C, Zollikofer CPE. 2017. Neomorphosis and heterochrony of skull shape in dog domestication. Scientific Reports 7:1-9. DOI: 10.1038/s41598-017-12582-2.

Geiger M, Haussman S. 2016. Cranial Suture Closure in Domestic Dog Breeds and Its Relationships to Skull Morphology. The Anatomical Record 299:412-420. DOI: 10.1002/ar.23313.

Geist V. 1974. Mountain Sheep. A Study in Behavior and Evolution. The University of Chicago Press. DOI: 10.1086/408061.

PeerJ reviewing PDF | (2019:04:36545:2:0:REVIEW 6 Aug 2019) 
400 Goodwin D, Bradshaw JWS, Wickens SM. 1997. Paedomorphosis affects agonistic visual 401 signals of domestic dogs. Animal Behaviour 53:297-304. DOI: 10.1006/anbe.1996.0370.

402 Goodwin D, Levine M, McGreevy P. 2007. Paedomorphosis: a novel explanation of physical 403 and behavioral differences in horses? In: Goodwin D, Heleski C, McGreevy P, McLean A, 404 Randle H, Skelly C, van Dierendonck M, Waran N eds. Proceedings of the 3rd 405 International Equitation Science Symposium. Michigan: MSU, 21.

406 Goodwin D, Levine M, McGreevy PD. 2008. Preliminary Investigation of Morphological 407 Differences Between Ten Breeds of Horses Suggests Selection for Paedomorphosis. $408 \quad$ Journal of Applied Animal Welfare Science 11:204-212. DOI: $409 \quad 10.1080 / 10888700802100918$.

410 Gould JS. 1980. The panda's thumb: More reflections in natural history. WW Norton \& 411 Company, Inc.

412 Habermehl K-H. 1975. Altersbestimmung bei Haus-und Labortieren. In: P. Parey,.

413 Hare B, Woods V. 2013. The genius of dogs. OneWorld Publications.

414 van Heel MC V, Kroekenstoel AM, van Dierendonck MC, van Weeren PR, Back W. 2006.

415 Uneven feet in a foal may develop as a consequence of lateral grazing behaviour induced by 416 conformational traits. Equine veterinary journal 38:646-51.

417 Hendricks BL. 2007. International encyclopedia of horse breeds. University of Oklahoma Press.

418 Hilzheimer M. 1926. Natürliche Rassengeschichte der Haussäugetiere.

419 Internationale FFE. 2015. Chapter IV: Ponies, Article 1042: Definitions. In: Veterinary

420 Regulations. Lausanne: FEI Fédération Equestre Internationale, 60.

421 Klingenberg CP, Barluenga M, Meyer A. 2002. Shape analysis of symmetric structures:

422 quantifying variation among individuals and asymmetry. Evolution; international journal of 423 organic evolution 56:1909-1920. DOI: 10.1554/0014-3820(2002)056.

424 Kolamunnage R, Kent JT. 2003. Principal component analysis for shape variation about an 425 underlying symmetric shape. Stochastic geometry, biological structure and images:137426139.

427 Kruska DCT, Steffen K. 2013. Comparative allometric investigations on the skulls of wild cavies 428 (Cavia aperea) versus domesticated guinea pigs (C. aperea f. porcellus) with comments on 429 430 the domestication of this species. Mammalian Biology 78:178-186. DOI: 10.1016/j.mambio.2012.07.002. 
431 MacLeod N. 2013. Landmarks and semilandmarks: differences without meaning and meaning 432 without difference. Palaeontological Association Newsletter 82:32-43.

433 Morey DF. 1992. Size, shape and development in the evolution of the domestic dog. Journal of 434 Archaeological Science 19:181-204. DOI: 10.1016/0305-4403(92)90049-9.

435 Porto A, de Oliveira FB, Shirai LT, de Conto V, Marroig G. 2009. The evolution of modularity 436 in the mammalian skull I: Morphological integration patterns and magnitudes. Evolutionary 437 Biology 36:118-135. DOI: 10.1007/s11692-008-9038-3.

438 Prideaux G. 2004. Systematics and evolution of the sthenurine kangaroos. University of 439 california publications in geological sciences.

440 R Core Team. 2016. R: A language and environment for statistical computing.

441 Radinsky L. 1984. Ontogeny and Phylogeny in Horse Skull Evolution. Evolution 38:1. DOI: $442 \quad 10.2307 / 2408541$.

443 Rohlf FJ, Slice D. 1990. Extensions of the Procrustes method for the optimal superimposition of 444 landmarks. Systematic Biology 39:40-59. DOI: 10.2307/2992207.

445 Sánchez-Villagra MR, Segura V, Geiger M, Heck L, Veitschegger K, Flores D. 2017. On the 446 lack of a universal pattern associated with mammalian domestication: differences in skull growth trajectories across phylogeny. Royal Society Open Science 4:170876. DOI: 10.1098/rsos. 170876 .

Shea BT, Gomez AM. 1988. Tooth scaling and evolutionary dwarfism: An investigation of 450 451 452 453 454 455 456 457 458 459 460 allometry in human pygmies. American Journal of Physical Anthropology 77:117-132. DOI: 10.1002/ajpa.1330770117.

Spencer LM. 1995. Morphological Correlates of Dietary Resource Partitioning in the African Bovidae. Journal of Mammalogy 76:448-471. DOI: 10.2307/1382355.

Tamagnini D, Meloro C, Cardini A. 2017. Anyone with a Long-Face? Craniofacial Evolutionary Allometry (CREA) in a Family of Short-Faced Mammals, the Felidae. Evolutionary Biology 44:476-495. DOI: 10.1007/s11692-017-9421-z.

Veitschegger K, Wilson LAB, Nussberger B, Camenisch G, Keller LF, Wroe S, SánchezVillagra MR. 2018. Resurrecting Darwin's Niata - anatomical, biomechanical, genetic, and morphometric studies of morphological novelty in cattle. Scientific Reports 8:9129. DOI: 10.1038/s41598-018-27384-3.

Verzani J. 2014. Using R for introductory statistics. CRC Press, Taylor \& Francis. 
462 Waller BM, Peirce K, Caeiro CC, Scheider L, Burrows AM, McCune S, Kaminski J. 2013.

463 Paedomorphic Facial Expressions Give Dogs a Selective Advantage. PLoS ONE 8:e82686.

464 DOI: 10.1371 journal.pone.0082686.

465 Wayne RK. 1986. Cranial Morphology Of Domestic And Wild Canids: The Influence Of

466 Development On Morphological Change. Evolution 40:243-261. DOI: 10.1111/j.1558-

$467 \quad$ 5646.1986.tb00467.x.

468 Wayne KW. 2001. Consequences of domestication: morphological diversity of the dog. In:

469 Ruvinsky A, Sampson J eds. The Genetics of the Dog. CAB International, 43-59.

470 Werneburg I, Geiger M. 2017. Ontogeny of domestic dogs and the developmental foundations of

471 carnivoran domestication. Journal of Mammalian Evolution 24:323-343. DOI:

$472 \quad 10.1007 / \mathrm{s} 10914-016-9346-9$.

473 Wilson G. 2012. Commissurotomy for Oral Access and Tooth Extraction in a Dwarf Miniature 474 Pony. Journal of Veterinary Dentistry 29:250-252. DOI: 10.1177/089875641202900406.

475 Wilson LAB. 2018. The evolution of ontogenetic allometric trajectories in mammalian 476 domestication. Evolution:867-877.

477 World Class Miniature Horse Registry.

478 


\section{Table $\mathbf{1}$ (on next page)}

Table 1. Description of morphological differences for three age classes of pony and horse breeds $(0,3,6)$ and age class 6 for both miniature breeds (Falabella, Shetland) for the studied sample by module (for a detailed sample composition see Table S1). 
Table 1: Description of morphological differences for three age classes of medium and large breeds $(0,3,6)$ and age class 6 for both

miniature breeds (Falabella, Shetland) for the studied sample by module (for a detailed sample composition see Table S1).

\begin{tabular}{|c|c|c|c|c|c|}
\hline \multirow[b]{2}{*}{ Module } & \multicolumn{3}{|l|}{ Medium and large breeds } & \multicolumn{2}{|l|}{ Miniature breeds } \\
\hline & Age class 0 & Age class 3 & Age class 6 & Falabella (age class 6) & Shetland (age class 6) \\
\hline $\begin{array}{l}\text { Anterior- } \\
\text { oral-nasal }\end{array}$ & \begin{tabular}{|l|} 
Short, very round, and \\
narrow premaxillare; no \\
incisors; maxillare in \\
diastema much narrower \\
as premaxillare; nasale and \\
diastema are straight; \\
diastema is very short
\end{tabular} & $\begin{array}{l}\text { Elongated and broader; Third } \\
\text { pair of incisors erupted; } \\
\text { elongated diastema; nasale is } \\
\text { straight or curved depending } \\
\text { on breed; maxillare in } \\
\text { diastema almost as broad as } \\
\text { premaxillare }\end{array}$ & $\begin{array}{l}\text { Elongated and broader; } \\
\text { premaxilla-maxilla suture } \\
\text { closed; elongated diastema; } \\
\text { nasale is straight or curved } \\
\text { depending on breed; } \\
\text { maxillare in diastema almost } \\
\text { as broad as premaxillare }\end{array}$ & $\begin{array}{l}\text { Short, round, and broad } \\
\text { premaxillare; maxillare in } \\
\text { diastema almost as broad } \\
\text { as premaxillare; all incisors } \\
\text { fully erupted; nasale is } \\
\text { concave }\end{array}$ & $\begin{array}{l}\text { Elongated and broader; } \\
\text { premaxilla-maxilla suture } \\
\text { closed; elongated diastema; } \\
\text { nasale is slightly convex; } \\
\text { maxillare in diastema almost } \\
\text { as broad as premaxillare }\end{array}$ \\
\hline Orbital & $\begin{array}{l}\text { Round or egg-shaped } \\
\text { depending on individual; } \\
\text { large compared to skull } \\
\text { length; post-orbital margin } \\
\text { is thin }\end{array}$ & $\begin{array}{l}\text { Round or egg-shaped } \\
\text { depending on individual; } \\
\text { medium compared to skull } \\
\text { length; postorbital margin has } \\
\text { thickened }\end{array}$ & $\begin{array}{l}\text { Round or egg-shaped } \\
\text { depending on individual; } \\
\text { small compared to skull } \\
\text { length; postorbital margin is } \\
\text { thick }\end{array}$ & $\begin{array}{l}\text { Round or egg-shaped } \\
\text { depending on individual; } \\
\text { medium compared to skull } \\
\text { length; postorbital margin } \\
\text { is thick }\end{array}$ & $\begin{array}{l}\text { Round or egg-shaped } \\
\text { depending on individual; } \\
\text { small compared to skull } \\
\text { length; postorbital margin is } \\
\text { thickened }\end{array}$ \\
\hline $\begin{array}{l}\text { Zygomatic- } \\
\text { pterygoid }\end{array}$ & \begin{tabular}{|l|} 
Frontal-zygomatic and \\
temporal-zygomatic suture \\
open; facial crest, \\
zygomatic, and temporal \\
form a straight line in \\
lateral view
\end{tabular} & $\begin{array}{l}\text { Frontal-zygomatic and } \\
\text { temporal-zygomatic suture } \\
\text { started to close; facial crest, } \\
\text { zygomatic, and temporal } \\
\text { form a straight line in lateral } \\
\text { view }\end{array}$ & $\begin{array}{l}\text { Frontal-zygomatic and } \\
\text { temporal-zygomatic suture } \\
\text { closed; facial crest and } \\
\text { zygomatic form a straight } \\
\text { line in lateral view; temporal } \\
\text { is curved from lateral view }\end{array}$ & $\begin{array}{l}\text { Frontal-zygomatic and } \\
\text { temporal-zygomatic suture } \\
\text { started closing; facial crest, } \\
\text { zygomatic, and temporal } \\
\text { form a curved line in } \\
\text { lateral view }\end{array}$ & $\begin{array}{l}\text { Frontal-zygomatic and } \\
\text { temporal-zygomatic suture } \\
\text { closed; facial crest and } \\
\text { zygomatic form a straight } \\
\text { line in lateral view; temporal } \\
\text { is slightly curved from } \\
\text { lateral view }\end{array}$ \\
\hline Cranial base & \begin{tabular}{|l|} 
Round; occipital condyle \\
and paracondylar process \\
have a similar length; \\
basisphenoid-presphenoid \\
and basisphenoid-occipital \\
suture open; basillar part \\
of the occipital is broad
\end{tabular} & $\begin{array}{l}\text { Elongated and distinct; } \\
\text { basisphenoid-presphenoid } \\
\text { started to close and } \\
\text { basisphenoid-occipital suture } \\
\text { open; basillar part of the } \\
\text { occipital is elongated; } \\
\text { paracondylar process is } \\
\text { slightly longer than } \\
\text { paracondylar process }\end{array}$ & $\begin{array}{l}\text { Elongated and very distinct; } \\
\text { basisphenoid-presphenoid } \\
\text { and basisphenoid-occipital } \\
\text { suture closed; basillar part of } \\
\text { the occipital is elongated; } \\
\text { paracondylar process is } \\
\text { much longer than } \\
\text { paracondylar process }\end{array}$ & $\begin{array}{l}\text { Short and broad; } \\
\text { basisphenoid-presphenoid } \\
\text { and basisphenoid-occipital } \\
\text { suture closed; basillar part } \\
\text { of the occipital is broad; } \\
\text { paracondylar process is } \\
\text { longer than paracondylar } \\
\text { process }\end{array}$ & $\begin{array}{l}\text { Elongated and very distinct; } \\
\text { basisphenoid-presphenoid } \\
\text { and basisphenoid-occipital } \\
\text { suture closed; basillar part of } \\
\text { the occipital is elongated; } \\
\text { paracondylar process is } \\
\text { much longer than } \\
\text { paracondylar process }\end{array}$ \\
\hline
\end{tabular}




\begin{tabular}{|l|l|l|l|l|l|}
\hline Cranial vault & $\begin{array}{l}\text { Occipital is not fused to } \\
\text { any other bone; very } \\
\text { round; frontal-parietal- } \\
\text { occipital doming; occipital } \\
\text { crest very small }\end{array}$ & $\begin{array}{l}\text { Frontal-parietal doming; } \\
\text { occipital elongated; occipitala } \\
\text { crest more pronounced; } \\
\text { occipital started fusing to } \\
\text { surrounding bones }\end{array}$ & $\begin{array}{l}\text { Frontal-parietal-occipital } \\
\text { flattened; occipital } \\
\text { elongated; occipital crest } \\
\text { very pronounced; occipital } \\
\text { mostly fused with } \\
\text { surrounding bones }\end{array}$ & $\begin{array}{l}\text { Frontal-parietal-occipital } \\
\text { doming; occipital } \\
\text { elongated; occipital crest } \\
\text { very pronounced; occipital } \\
\text { mostly fused with } \\
\text { surrounding bones }\end{array}$ & $\begin{array}{l}\text { Frontal-parietal-occipital } \\
\text { doming; occipital elongated; } \\
\text { occipital crest very } \\
\text { pronounced; occipital mostly } \\
\text { fused with surrounding } \\
\text { bones }\end{array}$ \\
\hline $\begin{array}{l}\text { Age } \\
\text { classification }\end{array}$ & $\begin{array}{l}\text { First post-natal stage, } \\
\text { before the eruption of the } \\
\text { first pair of incisors, up to } \\
1 \text { week old }\end{array}$ & $\begin{array}{l}\text { Time after the eruption of the } \\
\text { third pair of incisors until the } \\
\text { eruption of the first molar, six } \\
\text { month to one year, before } \\
\text { sexual maturity; weaning is } \\
\text { around 6 month of age }\end{array}$ & $\begin{array}{l}\text { Last age stage after the } \\
\text { eruption of the third molar, } \\
\text { from 4 years on, skeletal } \\
\text { maturity }\end{array}$ & Adult, age stage 6 & Adult, age stage 6 \\
\hline
\end{tabular}




\section{Figure 1}

Figure 1: Cranial shape comparison among two miniature breeds and a pony through ontogeny.

Examples of different cranial shapes during ontogeny from lateral view if available for each age class (0-6) for (A) Falabella and (B) Shetland (miniature breeds); and (C) Welsh (pony); each stage is represented by a different individual and all crania are scaled to the same length for comparison. Photographs by Laura Heck. 
B
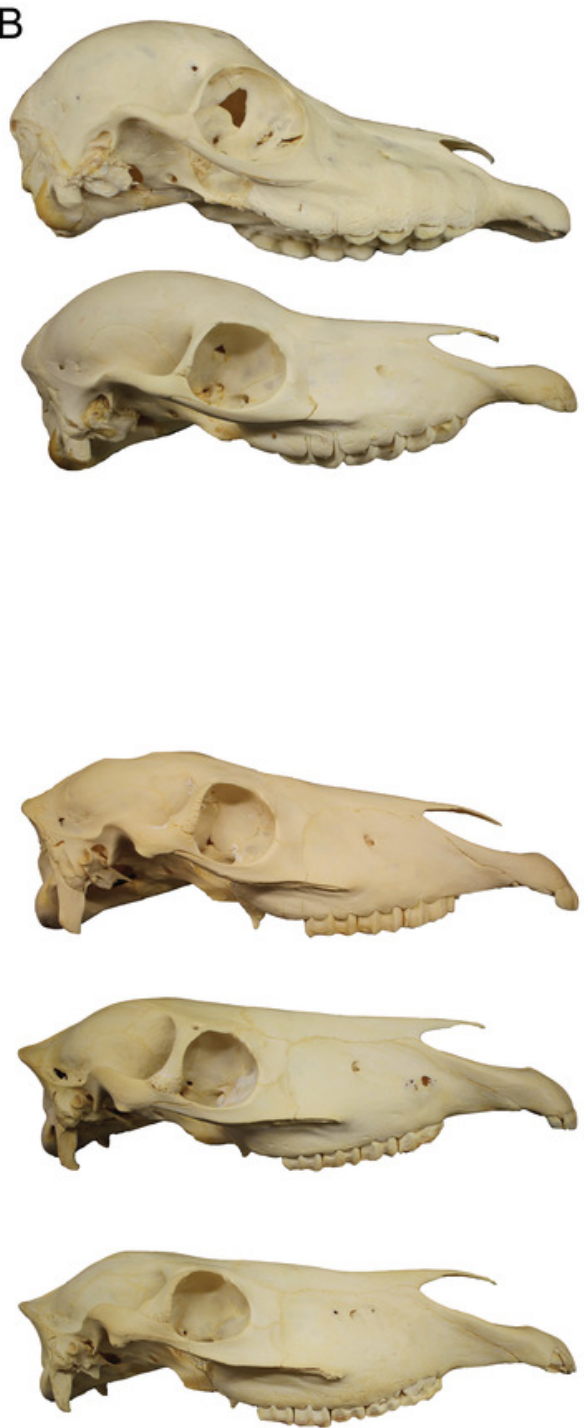

A

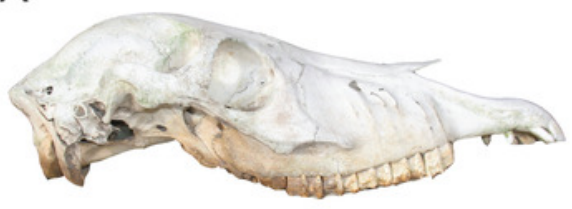

Falabella

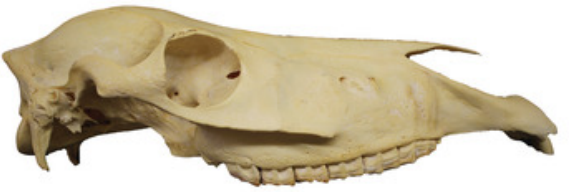

Shetland
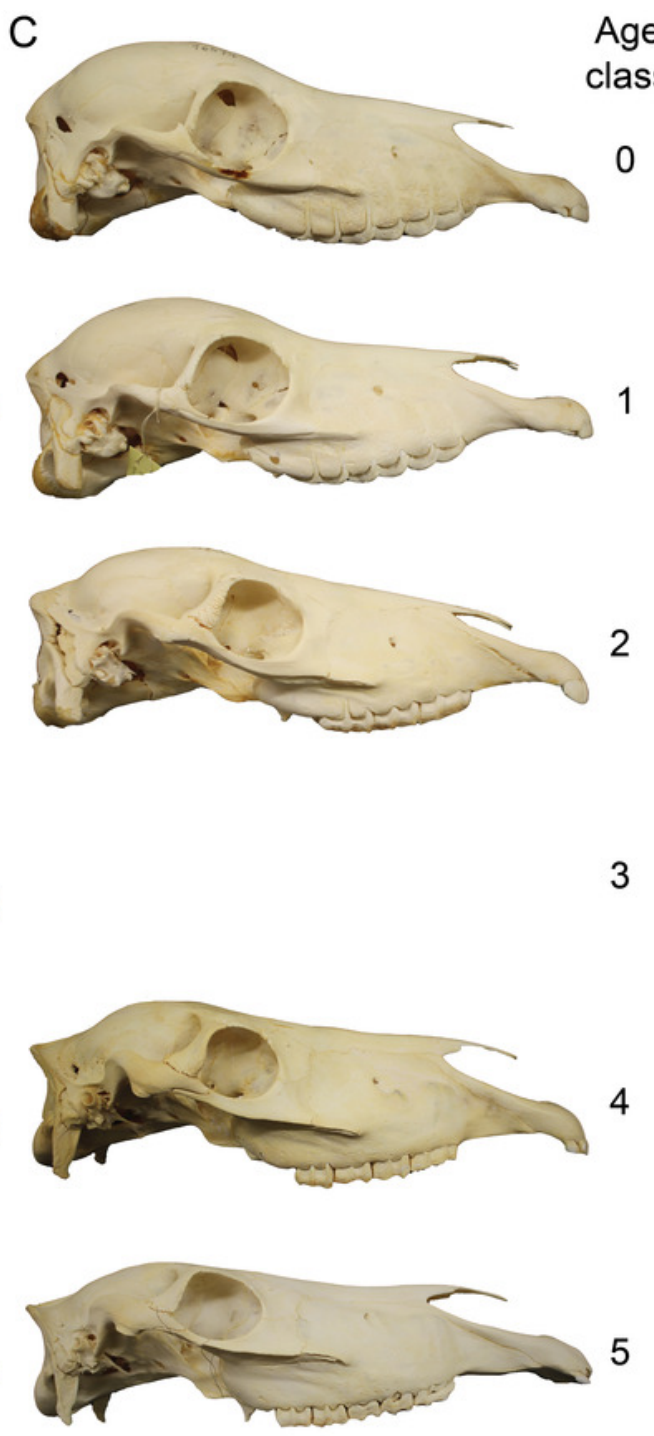

4

5

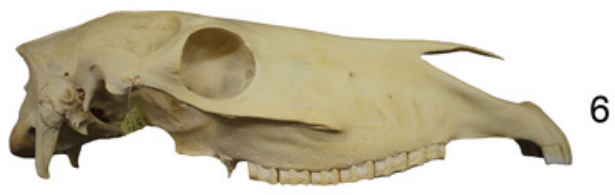

Welsh 


\section{Figure 2}

Cranial mean shapes for adult Falabella and Shetland, and for each analyzed age class of horses.

Cranial shapes in A) lateral and B) dorsal view for the average shape of each age class (0-6) of all horse specimens (for detailed sample composition see Table S1), C) lateral and D) dorsal view of adult Falabella and E) lateral and F) dorsal view of the average skull shape of adult Shetland (both miniature breeds); all crania are scaled to the same length for better comparison. 
A
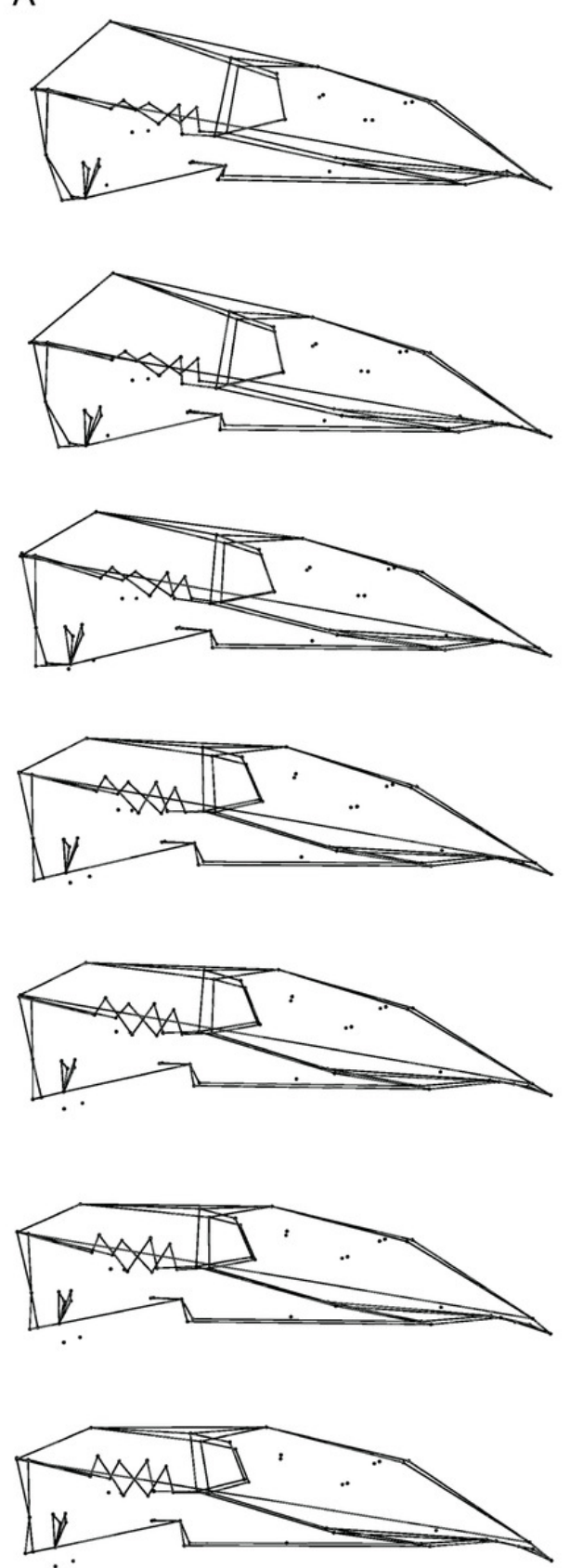

C

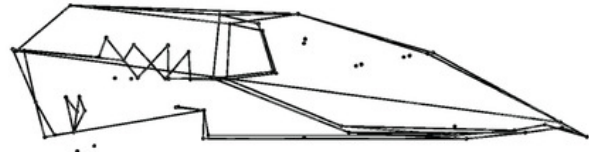

E

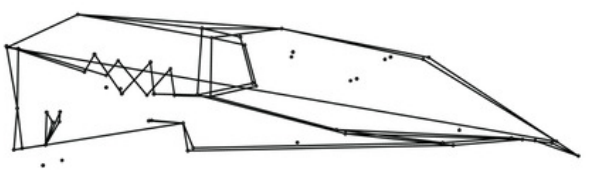

Age class

horses

0

1

2

3
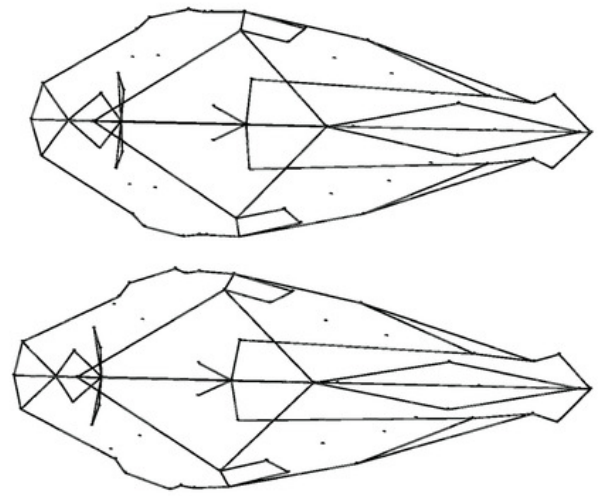

4

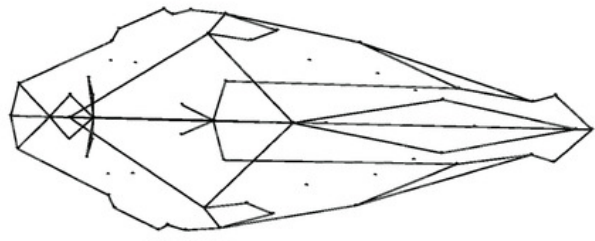

5

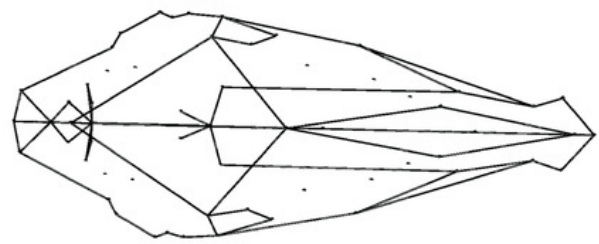

5

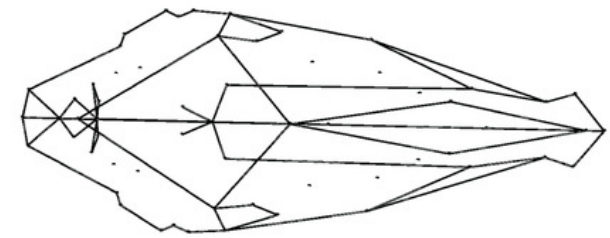

6
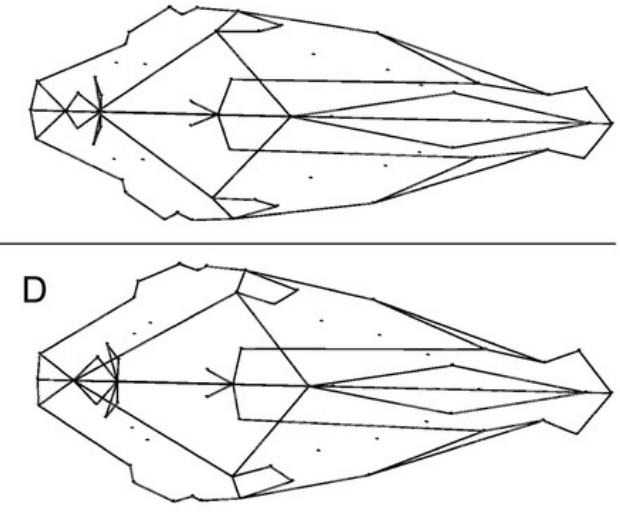

Shetland

adult

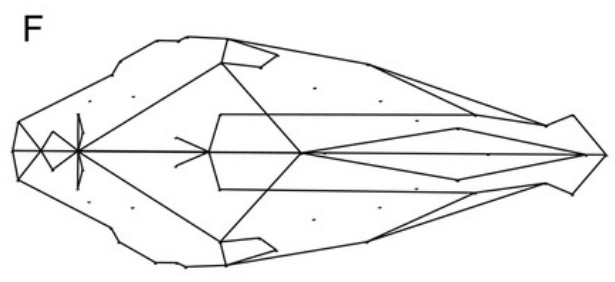




\section{Figure 3}

Figure 3. Principal component analysis of 194 specimens of 25 horse and 13 pony breeds, including two miniature breeds.
A) PC1-PC2 scatterplot shows ontogenetic trajectory for all analysed breeds (see Table S1 for details). Miniature breeds, breeds of extreme small size are highlighted with diamond and star shapes. Colours represent age classes. B) PC1-PC2 scatterplot as A) but the three groups - horses (filled black circles), ponies (filled grey diamonds) and miniature breeds (open triangle for Shetland and star for Falabella) are highlighted. C) Dorsal and D) lateral views of the cranium show the shape changes along $P C 1$, adult shape in grey and juvenile shape in black. TPS-grids can be found in Fig S3. 

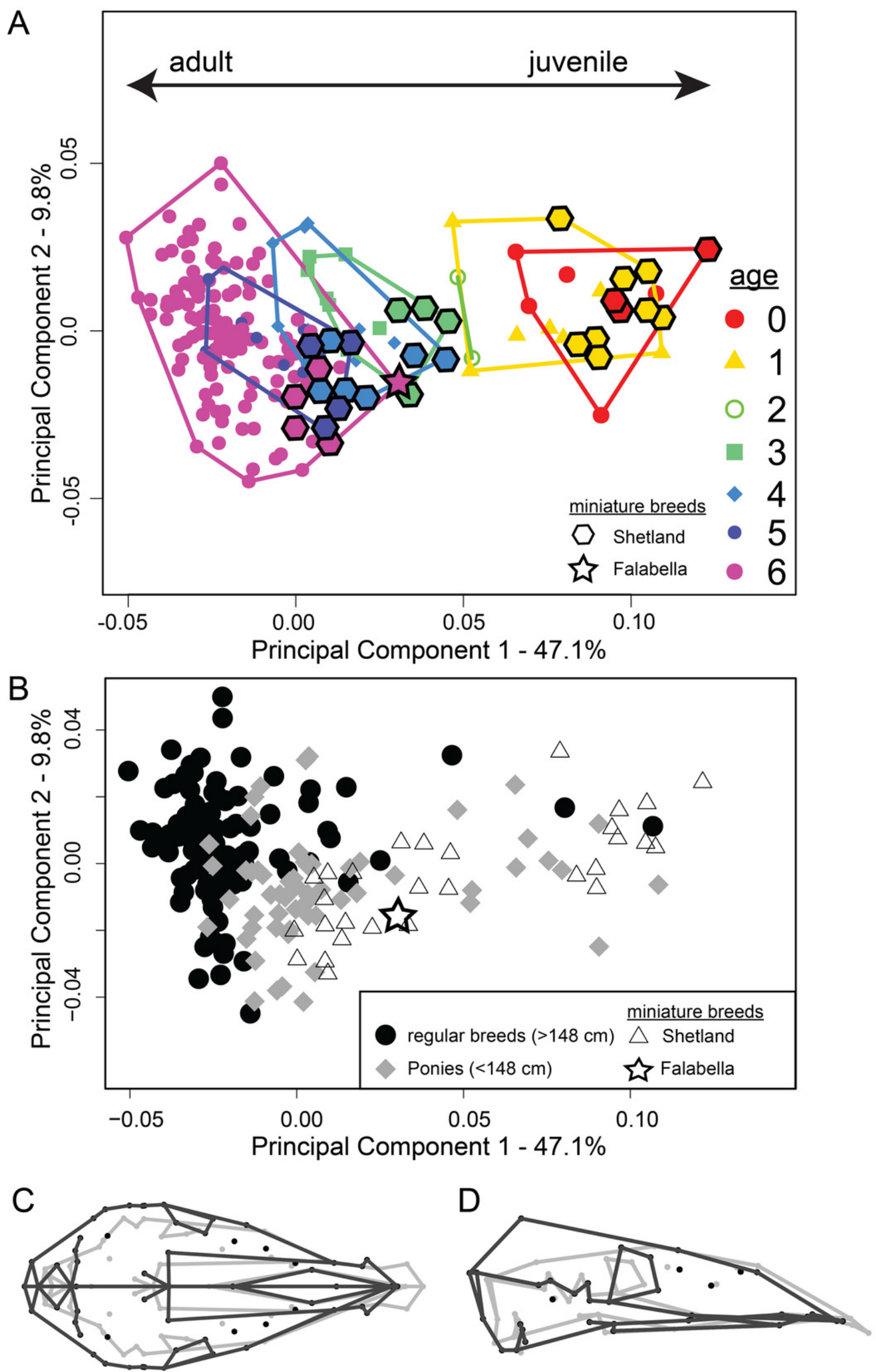


\section{Figure 4}

Figure 4. Allometric trend in pony and horse skull shapes.

(A) Regression of shape on log centroid size and (B) predicted shape values from regression of shape on log centroid size. Ponies are shown in stars, horses in open squares. The position of adult Falabella skull is highlighted. Colours correspond to age classes. 

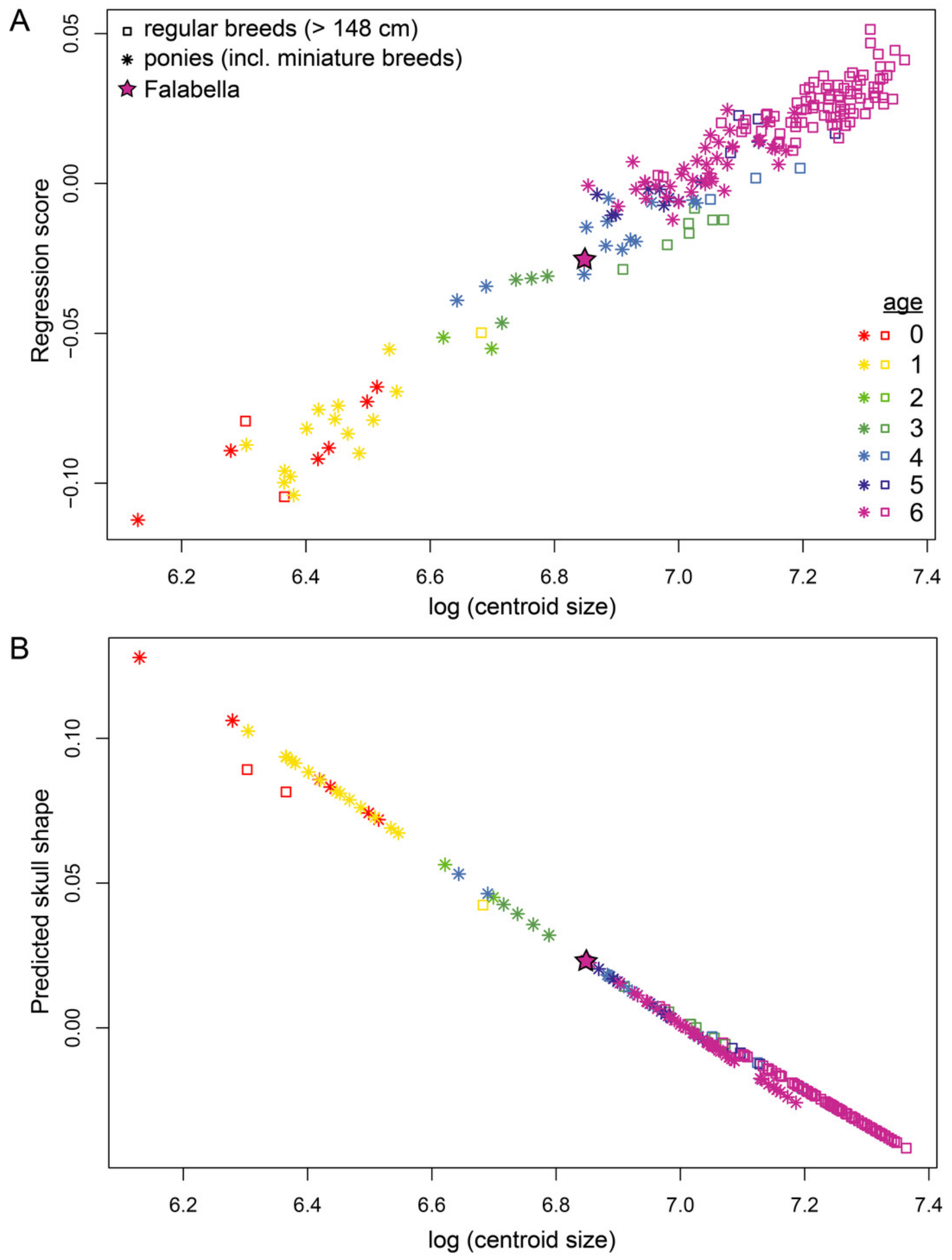


\section{Figure 5}

Figure 5. Testing for "paedomorphic" features.

(A-C) Orbit to cranial length ratio, basciranium to palate length ratio, and angle between basicranium and palate, per age category, all breeds except for miniature breeds as boxplots in grey, and Shetland (diamonds) and Falabella (star) as miniature breeds superimposed in black. (D) Adult cranial length in relation to maximal wither height with $95 \%$ confidence interval (solid line) and prediction interval (dotted line), and regression line (red). Regression line and $95 \%$ prediction curves were extended to smaller wither heights to accommodate the cranial length of the miniature breeds in the same plot. (E) Adult cranial length to wither height ratios were plotted against breed in ascending order from the smallest breed, the Falabella, to the largest breed, the Shire horse. Abbreviations for the breeds: fab: Falabella; she: Shetland; exm: Exmoor pony; wel: Welsch, mon: Mongolian; kon: Konik; bos: Bosnian pony; huz: Huzule; scp: Scottish pony; ice: Icelandic Horse; hny: Hackney; arb: Arab; grp: German Riding pony; grb: Grisons; Ipz: Lipizzan; piz: Pinzgau; nor: Norik; ano:Anglo-Norman; thb: English Thoroughbred; hun: Hungarian; trk: Trakehner; han: Hannoverian, odb:

Oldenburgian; suf: Suffolk; kdr: Kladrubian; blg: Belgian Draft; hol: Holstein; cds: Clydesdale; shi: Shire; for the ten breeds that were included in 3D GM but not linear analyses, no information on average wither height could be found. 

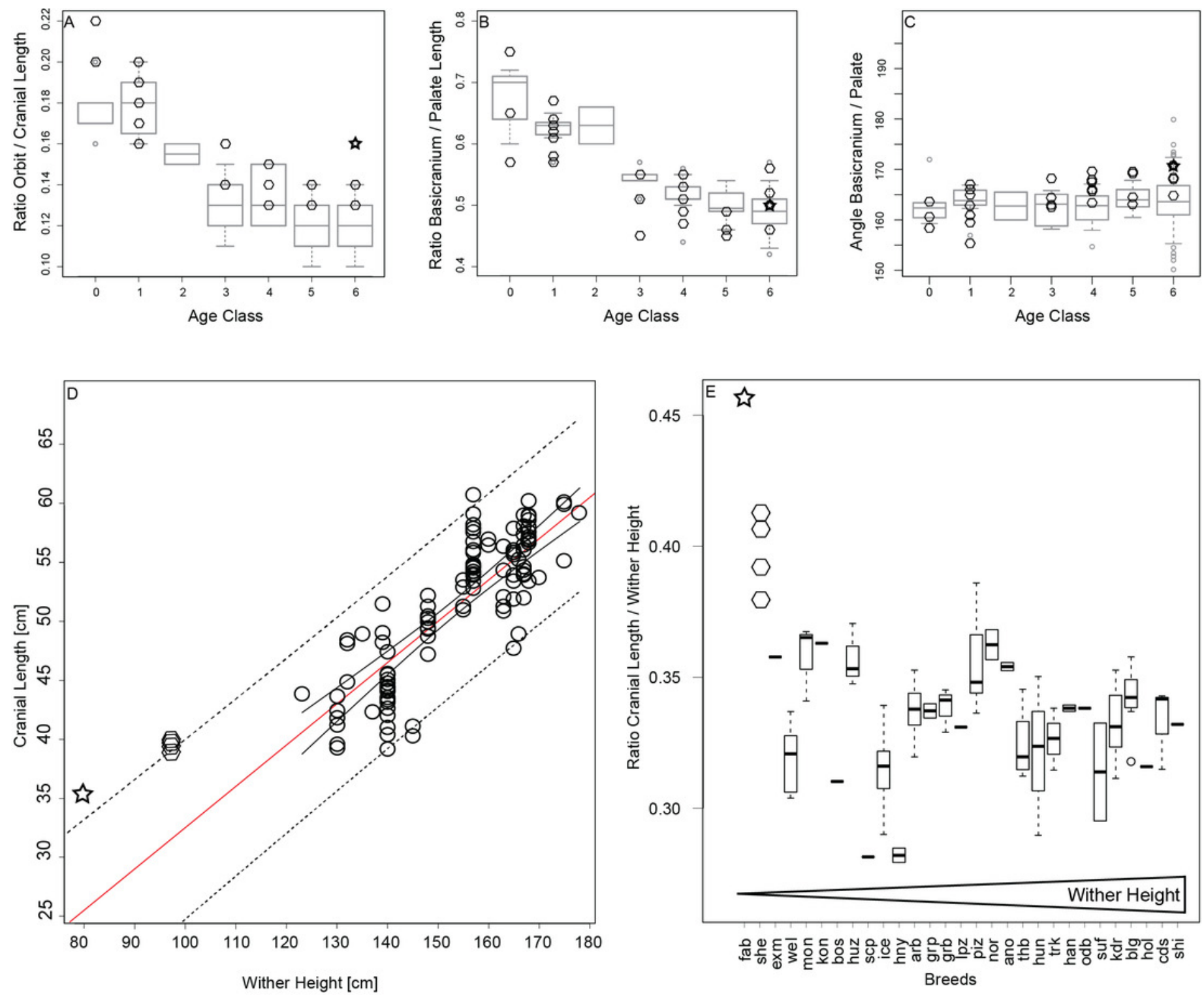